\title{
Penerapan Metode Organization Goal-Oriented Requirements Engineering (OGORE) untuk Pembangunan Sistem Pendaftaran Klinik Fisioterapi
}

\author{
Fransiskus Adikara $^{\# 1}$, Sandfreni ${ }^{\# 2}$, Revando Prastya ${ }^{\# 3}$ \\ ${ }^{\#}$ Fakultas Ilmu Komputer, Universitas Esa Unggul \\ Jl. Arjuna Utara No.9, RT.1/RW.2, Duri Kepa, Kec. Kb. Jeruk, Kota Jakarta Barat, Daerah Khusus Ibukota Jakarta 11510 \\ ${ }^{1}$ fransiskus.adikara@esaunggul.ac.id \\ ${ }^{2}$ sandfreni@esaunggul.ac.id \\ 3revandod esaunggul.ac.id
}

\begin{abstract}
Abstrak - Fisioterapi adalah pengobatan terhadap penderita yang mengalami kelumpuhan atau gangguan otot dengan tujuan melatih otot tubuh agar dapat berfungsi secara normal. Fisioterapis merupakan salah satu bentuk pendukung pengobatan medis yang diberikan oleh berbagai klinik, yang salah satunya tersedia di Klinik Fisioterapi daerah Jakarta Barat. Klinik Fisioterapi ini masih mengandalkan sistem pendaftaran melalui telepon untuk proses administrasi pendaftaran pasien, sehingga pasien yang akan terapi harus menghubungi admin klinik minimal 1 hari sebelum melakukan terapi. Sesudah itu, secara manual, penerima telepon mengecek jadwal terapis yang tersedia. Untuk mengatasi permasalahan ini, pemanfaatan teknologi informasi dan komunikasi bisa menjadi solusi. Penggunaan perangkat telepon pintar berbasis Android saat ini terus mengalami peningkatan. Pasien dapat menggunakan sistem berbasis Android untuk mendaftar pada jadwal terapi yang tersedia menggunakan perangkat telepon pintar tanpa harus menelpon terlebih dahulu ke klinik. Untuk mempermudah proses administrasi saat kedatangan pasien, sistem pemesanan terapi juga dilengkapi $Q R$ Code pada sistemnya yang dapat digunakan untuk daftar ulang. Metode Organization Goal-Oriented Requriments Engineering (OGORE) digunakan untuk mengelisitasi kebutuhan dan spesifikasi sistem agar sistem yang dibangun lebih dapat memenuhi kebutuhan organisasi dibandingkan kebutuhan pengguna yang sudah terbiasa dengan cara manual selama ini berjalan. Dengan menggunakan metode OGORE pada penelitian ini diharapkan dapat mencapai tujuan sistem pendaftaran klinik fisioterapi dalam mempercepat proses pendaftaran pasien dan meningkatkan kualitas pelayanan bagi pasien yang akan melakukan Fisioterapi.
\end{abstract}

Kata kunci- Rekayasa Perangkat Lunak, Rekayasa Kebutuhan, Organization Goal-Oriented Requirements Engineering, Sistem Berbasis Android, Sistem Klinik

\section{PENDAhUluan}

Fisioterapis merupakan seorang spesialis yang membantu menyembuhkan pasien melalui metode fisioterapi. Secara spesifik menurut WCPT (World Confederation for Physical Therapy), fisioterapis adalah pekerja kesehatan profesional yang bekerja untuk orang dari segala usia yang bertujuan untuk melestarikan, meningkatkan kesehatan, memulihkan fungsi, dan ketergantungan ketika individu memiliki ketidakkemampuan atau adanya masalah gangguan disebabkan oleh kerusakan fisik, psikis, dan sebagainya. Fisioterapi adalah pengobatan terhadap penderita yang mengalami kelumpuhan atau gangguan otot dengan tujuan melatih otot tubuh agar dapat berfungsi secara normal [1]. Fisioterapis merupakan salah satu bentuk pendukung pengobatan medis yang diberikan oleh berbagai klinik salah satunya adalah Klinik Fisioterapi yang ada di salah satu universitas daerah Jakarta Barat[2].

Klinik Fisioterapi ini merupakan salah satu klinik fisioterapi terbaik di Jakarta, terbukti dengan banyaknya sekali atlet-atlet yang sudah beberapa kali datang untuk berobat[3][4]. Dalam menjalankan administrasinya Klinik Fisioterapi ini masih mengandalkan sistem pendaftaran via telepon sehingga pasien yang akan terapi harus menghubungi admin klinik 1 hari sebelum melakukan terapi, lalu karyawan administrasi (admin) akan menelpon bagian terapis untuk menannyakan jadwal yang pas untuk praktek, jika waktu untuk terapi sudah di tentukan oleh admin dan terapis maka admin akan menelepon kembali ke pasien yang akan diterapi untuk memberitahukan kapan pasien harus datang ke Klinik.

Dengan sistem yang berjalan sekarang untuk pendaftaran jadwal terapi harus melewati proses yang panjang dan memakan waktu dari mulai harus menelepon admin sampai menerima konfirmasi terapis tentang jadwal 
terapi yang akan di lakukan. Admin klinik yang menerima panggilan telepon hanya satu orang sehingga pasien yang mau mendaftar jadi terbatas. Pasien juga sering mengeluh karena pada saat menelpon ke klinik tidak di angkat oleh admin disebabkan admin sedang menerima panggilan dari pasien lain. Saat ini Klinik Fisioterapi ini dapat mengobati pasien 10 sampai 20 dalam satu hari.

Berdasarkan kondisi yang dijelaskan, pihak klinik membutuhhkan solusi untuk mempermudah proses pendaftaran terapi, khususnya bagi para lansia atau para atlet-atlet yang membutuhkan pelayanan dengan cepat. Klinik diharapkan bisa mempercepat proses administrasi tanpa repot harus menelepon para terapis dan pasien beberapa kali untuk konfirmasi.

Saat ini penggunaan teknologi informasi dan komunikasi sudah menjadi gaya hidup masyarakat. Penggunaan telepon pintar sudah menjadi hal yang umum, dan saat ini telepon pintar berbasis Android masih dominan digunakan saat ini[5]. Oleh karena itu, solusi bagi Klinik Fisioterapi pada penelitian ini adalah sebuah sistem pendaftaran klinik berbasis Android untuk mempersingkat proses pendaftaran yang ada. Sistem yang dikembangkan pada penelitian ini di bagi menjadi 2 bagian utama yaitu, sistem berbasis web untuk admin Klinik Fisioterapi dan sistem berbasis Android yang di gunakan oleh pasien dan admin yang ingin membuat janji untuk terapi menggunakan telepon pintar tanpa harus menelepon terlebih dahulu ke klinik.

Untuk mengembangkan sistem ini, kami menggunakan teknik rekayasa kebutuhan berorientasi pada tujuan organisasi (Organization Goal-Oriented Requirements Engineering/OGORE)[6]. Dari Goal Tree Model (GTM) yang diperoleh dari proses elisitasi kebutuhan akan didefinisikan kebutuhan fungsional dan bukan fungsional dari sistem pendaftaran klinik Fisioterapi ini. Berdasarkan kebutuhan sistem tersebut dibuatkanlah sistem pendaftaran Klinik Fisioterapi yang akan digunakan. Penggunaan metode OGORE ini diharapkan agar sistem yang dibuat dapat memenuhi kebutuhan organisasi dalam mencapai tujuan organisasi tersebut, sehingga dapat sesuai pemanfaatannya. Dengan adanya penelitian ini akan mendemonstrasi penggunaan metode OGORE untuk mengembangkan sistem dikombinasikan dengan metode Rapid Application Development[7] dalam rangka keseluruhan pembangunan sistem sehingga dapat digunakan oleh para peneliti lainnya sebagai salah satu alternatif metode pengembangan sistem lainnya.

Dengan adanya sistem pendaftaran Klinik Fisioterapi UEU ini diharapkan pelayanan admin klinik dapat lebih cepat dan termonitor karena tercatat secara digital. Penjelasan metodologi penelitian yang dikerjakan untuk mengembangkan sistem ini akan dibahas pada bagian ke 2, dilanjutkan dengan tinjauan pustaka, proses pembangunan sistem pendaftaran, dan diakhiri kesimpulan pada bagian akhir makalah ini.

\section{Metodologi PenElitian}

Pada penelitian ini, metodologi penelitian yang dilaksanakan adalah:

1. Studi Pustaka untuk mendapatkan tinjuan pustaka dari metode OGORE sebagai sebuah metode rekayasa kebutuhan yang berorientasi pada tujuan serta pemodelan hasil elisitasi kebutuhan berupa Goal Tree Model (GTM) yang akan digunakan dalam proses elisitasi kebutuhan sistem pendaftaran klinik.

2. Studi Pustaka untuk mendapatkan tinjauan pustaka dari penelitian terkait sistem pendaftaran klinik yang pernah dikembangkan sebelumnya.

3. Mencari data dan informasi dari proses pendaftaran pada klinik Fisioterapi.

4. Menggunakan metode OGORE untuk melakukan elsisitasi kebutuhan.

5. Memodelkan hasil dari proses elisitasi kebutuhan dalam bentuk Goal Tree Model (GTM).

6. Mendefinisikan kebutuhan fungsional dan bukan fungsional dari sistem pendaftaran klinik UEU.

7. Membangun sistem penfataran klinik UEU menggunakan metode Rapid Application Development.

8. Menguji sistem yang dibangun apakah sudah memenuhi kebutuhan fungsional dan bukan fungsional yang sudah ditetapkan.

Berdasarkan metodologi diatas, bagian makalah ini berikutnya akan dibagi menjadi pembahasan mengenai Tinjauan Pustaka (langkah 1 dan 2), dilanjutkan dengan proses pembangunan sistem pendaftaran (langkah 3 sampai dengan 8), diakhiri dengan kesimpulan.

\section{TINJAUAN PUSTAKA}

Pada tinjauan pustaka ini akan membahas mengenai penelitian-penelitian yang terkait dengan Organization Goal-Orietend Requirements Engineering (OGORE) dan Rapid Application Development (RAD) sebagai dasar utama metode untuk pengembangan sistem pendaftaran klinik.

\section{A. Metode Organization Goal-Oriented Requirements Engineering (OGORE)}

Saat ini ada beberapa metode rekayasa kebutuhan berorientasi pada tujuan yang masih dikembangan dan digunakan dalam proses pengembangan sistem. Selain KAOS[8], iStar (i*)[9], dan GRL[10], pada penelitian sebelumnya kami sudah mengembangkan metode rekayasa kebutuhan berorientasi pada tujuan yang didapatkan dari tujuan organisasi. Rekayasa kebutuhan berorientasi pada tujuan organisasi (OGORE) [11] mengelisitasi kebutuhan berdasarkan visi, misi, dan tujuan organisasi sebagai bahan utama mendapatkan fungsi-fungsi sistem. Dengan metode ini diharapkan fungsional dari sistem mempunyai prioritas memenuhi kebutuhan organisasi daripada berdasarkan pada kepentingan pribadi pengguna sistem dalam melakukan transaksi. 
Proses utama dari OGORE adalah proses elisitasi kebutuhan dan proses perbaikan serta analisis kebutuhan. Pada penelitian ini akan menggunakan proses elisitasi kebutuhan, yang terdiri dari 3 (tiga) aktivitas yaitu mendifinisikan tujuan organisasi dari visi dan misi organisasi, memetakan tujuan sistem dan mengintegrasikan KPI. Keseluruhan aktivitas utama prosesnya digambarkan pada diagram alir proses OGORE (Gambar 1).

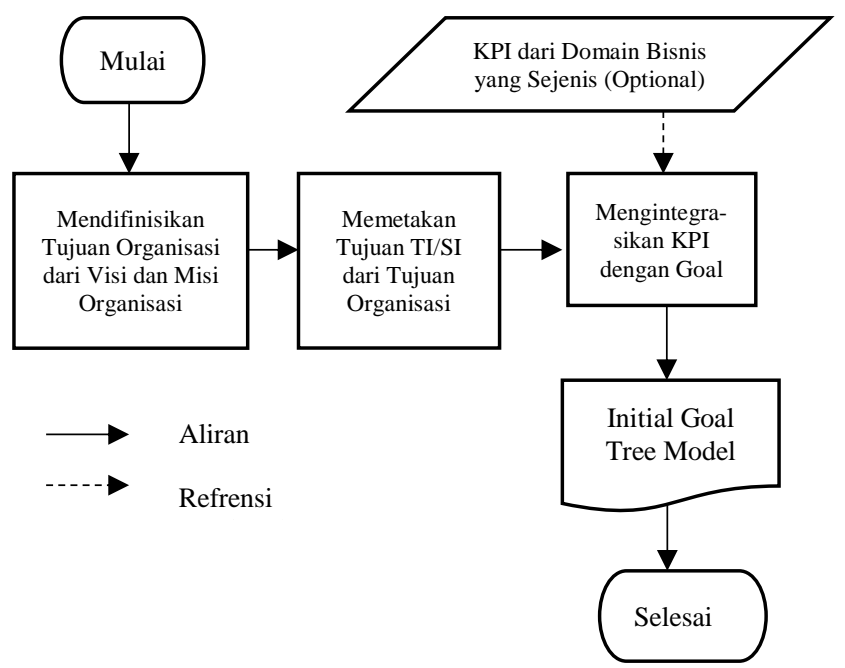

Gambar. 1 Diagram Alir Proses Elisitasi OGORE
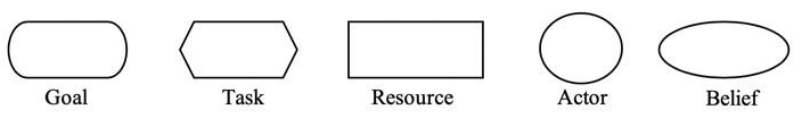

Gambar. 2 Elemen-elemen GTM pada OGORE

Hasil dari OGORE akan dimodelkan dalam bentuk diagram. Pemodelan goal beserta turunannya pada OGORE menggunakan Goal Tree Model (GTM) yang diadaptasi dari Goal Requirement Language (GRL). Elemen-elemen GTM pada OGORE (Gambar 2) yang terkait juga dengan elemen-elemen sistem informasi adalah sebagai berikut:

1) Goal: yaitu tujuan organisasi, tujuan bisnis, tujuan IT, dan tujuan SI yang ingin dicapai oleh organisasi. Pengukuran goal ini bersifat kuantitatif dan memiliki KPI pada setiap goal. Goal ini akan berhubungan dengan kebutuhan fungsional (functional requirements). Elemen ini berhubungan dengan elemen software dan output pada sistem informasi yang akan dikembangkan.

2) Task: yaitu sebuah rangkaian solusi atau serangkaian proses bisnis untuk dapat mencapai goal yang telah didefinisikan. Elemen ini berhubungan dengan elemen proses pada sistem informasi yang akan dikembangkan.

3) Resource: adalah sumber daya yang dibutuhkan untuk mencapai dan melengkapi goal dan task. Elemen ini berhubungan dengan elemen hardware serta database pada sistem informasi yang akan dikembangkan.
4) Actor: merupakan stakeholder dari proses bisnis yang menginginkan agar goal dapat dicapai, taks dapat dikerjakan, dan recource tersedia. Elemen ini berhubungan dengan elemen sumber daya manusia (brainware) pada sistem informasi yang akan dikembangkan.

5) Belief: mewakili interprestasi dan prinsip dasar yang dipercaya dari sebuah keseluruhan proses bisnis. Elemen ini berhubungan dengan elemen proses pada sistem informasi yang akan dikembangkan.

6) Constraint: adalah interprestasi dari sebuah norma dan keadaan yang memberikan batasan pencapaian dari goal yang ditetapkan. Elemen ini berhubungan dengan elemen proses pada sistem informasi yang akan dikembangkan.

Beberapa penelitian tentang sistem penjadwalan dan pendaftaran memang sudah pernah dilakukan sebelumnya. Diantaranya penelitian karya Mara Destiningrum dan Qadhli Jafar Adrian yang membahas tentang adanya sistem Informasi Penjadwalan Dokter dapat memberikan informasi jadwal praktik dokter dengan cepat dan akurat dan menjadikan proses penjadwalannya lebih efisien[12]. Di bandingan dengan sistem yang akan di usulkan oleh penulis, sistem ini kurang lengkap fungsinya karena hanya dapat melihat jadwal dokter praktek tanpa bisa sekaligus mendaftar untuk pemeriksaannya, sehingga pasien yang akan akan berobat tidak bisa mendaftar via online dan harus tetap datang ke klinik atau rumah sakit.

Penelitian lainnya telah dilakukan oleh Rin Rin Meilani Salim yang membahas tentang sistem dengan tujuan untuk menyajikan informasi secara cepat, tepat, dan akurat. Salah satu yang dapat dimanfaatkan adalah pengembangan sistem informasi klinik berbasis web yang dibuat dengan tujuan agar sistem informasi dan informasi dapat diakses oleh penggunanya di setiap komputer tanpa harus meng-install sistem informasi tersebut dan diakses tanpa mengenal waktu jam kerja staf klinik. Pengembangan sistem informasi klinik berbasis web ini diberi nama Sifonik[13]. Di bandingan dengan sistem yang akan di usulkan oleh penulis, sistem ini kurang fleksibel karena hanya dapat di gunakan di web browser komputer desktop. Sifonik ini juga hanya dapat menampilan informasi pendaftaran di klinik, dan tidak ada fitur untuk pendaftaran oleh pasien langsung, sehingga sistem ini hanya bisa di gunakan oleh karyawan yang bekerja di klinik tersebut.

Penelitian lainnya adalah karya Aslam Fatkhudin, Dwi Nur Alifiani. Pada penelitian tersebut, mereka membangun aplikasi android dengan menggunakan kerangka kerja Ionic untuk pembangunannya. Aplikasi ini dilengkapi dengan fitur pemesanan dengan syarat-syarat yang perlu diperhatikan sehingga memudahkan pasien untuk mengetahui informasi pendaftaran[14].

Berdasarkan penelitian sebelumnya yang sudah dijelaskan paragraf diatas, maka pada penelitian ini kami akan menggunakan metode OGORE untuk mendapatkan kebutuhan-kebutuhan sistem berdasarkan tujuan dari organisasi, lalu menggunakan metode RAD untuk proses 
pengembangan sistemnya. Sistem ini akan dikonstruksi pada Android Studio untuk aplikasi mobile-nya dan menggunakan PHP untuk mengkonstruksi sistem web adminnya. Pada sistem yang dibangun juga menggunakan QR Code[15] yang berfungsi alat untuk daftar ulang pasien, sehingga pasien yang sudah datang ke klinik tidak perlu lagi mengisi buku absen atau form daftar ulang yang di sediakan oleh pihak klinik, cukup menunjukan $Q R$ Code dan petugas klinik nanti akan mepindai $Q R$ Code milik pasien dan datanya akan masuk ke sistem admin sebagai bukti daftar ulang pasien.

\section{B. Metode Pembangunan Sistem Menggunakan Rapid Application Development (RAD)}

Rapid Aplication Development (RAD) [7] adalah proses model perangkat lunak incremental (bertahap) yang menekankan siklus pengembangan yang singkat . Model RAD adalah sebuah adaptasi pendekatan pembangunan sistem dengan "kecepatan tinggi", di mana pembangunan sistem dilakukan secara cepat dicapai dengan menggunakan pendekatan konstruksi berbasis komponen, dan penggunaan ulang terhadap beberapa komponen yang sudah ada sebelumnya. RAD memiliki tahapan-tahapan utama (Gambar 3) yaitu:

1) Perencanaan Kebutuhan (Requirement Planning): yaitu proses untuk mengelisitasi kebutuhan sistem, baik kebutuhan fungsional maupun kebutuhan bukan fungsional.

2) Ruang Kerja Perancangan (Workshop Design): terdiri dari perancangan sistem dan konstruksi (coding) sistem yang dilakukan secara berulang dari versi awal sampai mendapatkan versi terakhir yang siap untuk digunakan dengan cara melakukan cut over (peralihan).

3) Implementasi: merupakan proses uji coba sistem pada lingkungan yang akan menggunakan.

Pada bagian berikutnya akan membahas tahapantahapan pembangunan sistem sesuai metode RAD.

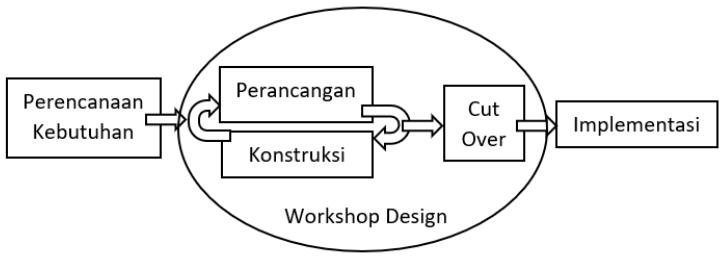

Gambar. 3 Proses metode rapid application development

\section{Proses PEMbangunan Sistem PENDAFTARAN DAN PEMESANAN TERAPIS BERBASIS ANDROID PADA KLINIK FISIOTERAPI}

\section{A. Proses Perencanaan Kebutuhan (Requirements Planning)}

Penelitian yang akan di laksanakan pada bulan Oktober, yang bertempat di Klinik Fisioterapi di sebuah Universitas daerah Jakarta Barat, Daerah Khusus Ibukota Jakarta. Klinik Fisioterapi ini terbuka untuk seluruh mahasiswa, karyawan, dan juga masyarakat umum. Banyak atlit Nasional Indonesia yang diterapi pada klinik ini, seperti
Irfan Bachdim, Diego Michiels, Bayu Pradana, dan lainnya. Selain itu terapis klinik Fisioterapi ini juga sering mengirimkan terapisnya pada acara olahraga tingkat nasional maupun internasional.

Langkah awal metode elisitasi kebutuhan menggunakan OGORE yaitu mendefinisikan tujuan organisasi dari visi dan misi klinik. Visi dari klinik adalah menjadi klinik yang dapat memberikan pelayanan fisioterapi terbaik di tingkat nasional dan internasional. Misi dari klinik adalah menyelenggarakan pelayanan fisioterapi khususnya Manual Terapi, Fisioterapi Olahraga dan Latihan Fungsi kepada masyarakat, dan menyediakan peralatan terapi yang mendukung proses pelayanan fisioterapi dengan standar internasional. Dari visi dan misi tersebut, maka tujuan dari klinik adalah meningkatkan pelayanan kesehatan kepada masyarakat khususnya yang membutuhkan pelayanan fisioterapi, meningkatkan kemampuan para terapis untuk dapat memberikan pelayanan fisioterapi dengan standar internasional, dan meningkatkan pengalaman mahasiswa dalam praktek pelayanan fisioterapi.

Langkah berikutnya yaitu memetakan tujuan Teknologi Informasi/Sistem Informasi dari tujuan organisasi. Salah satu tujuan organisasi adalah meningkatkan pelayanan kesehatan kepada masyarakat khususnya yang membutuhkan pelayanan fisioterapi, tujuan ini dipetakan menjadi tujuan sistem informasi yaitu meningkatkan kenyamanan pelanggan klinik dalam proses pelayanan fisioterapi di klinik. Tujuan sistem informasi ini akan menjadi dasar untuk elemen-elemen lainnya sesuai metode OGORE yang telah dijelaskan pada tinjauan pustaka.

Setelah metode OGORE dilaksanakan, maka akan dihasilkan Goal Tree Model sebagai dasar untuk menentukan kebutuhan fungsional dan bukan fungsional dari sistem yang akan dibangun (Gambar 4). Kebutuhan fungsional dari sistem yang akan dibangun adalah:

1. Fungsi pendaftaran pengguna

2. Fungsi penjadwalan terapis

3. Fungsi pendaftaran terapi

4. Fungsi daftar ulang

Sedangkan kenutuhan bukan fungsional dari sistem yang dibangun adalah:

1. Sistem mempunyai fitur keamanan pengguna

2. Sistem dapat diakses dari mana saja

3. Sistem mempunyai keamanan untuk daftar ulang

\section{B. Ruang Kerja Perancangan (Workshop Design)}

Ruang kerja perancangan merupakan tahapan melakukan perancangan sistem dan konstruksi sistem. Dalam perancangan sistem ini menggunakan diagram UML Use Case Diagram dan ER-Diagram untuk mendefinisikan fungsi dan hubungan sistem basis data.

Berdasarkan Goal Tree Model yang diperoleh dari tahapan perencanaan kebutuhan, maka diterjemahkan pada proses perancangan ini dalam bentuk Use Case Diagram, untuk mengambarkan hubungan antara setiap fungsi yang ada dengan Aktor yang berinteraksi (Gambar 5). Jadi seperti yang didefinisikan pada proses elisitasi kebutuhan, 
fungsi utama dari sistem ada 4 (empat) yang definisinya ada pada Tabel I, II, III, dan IV.

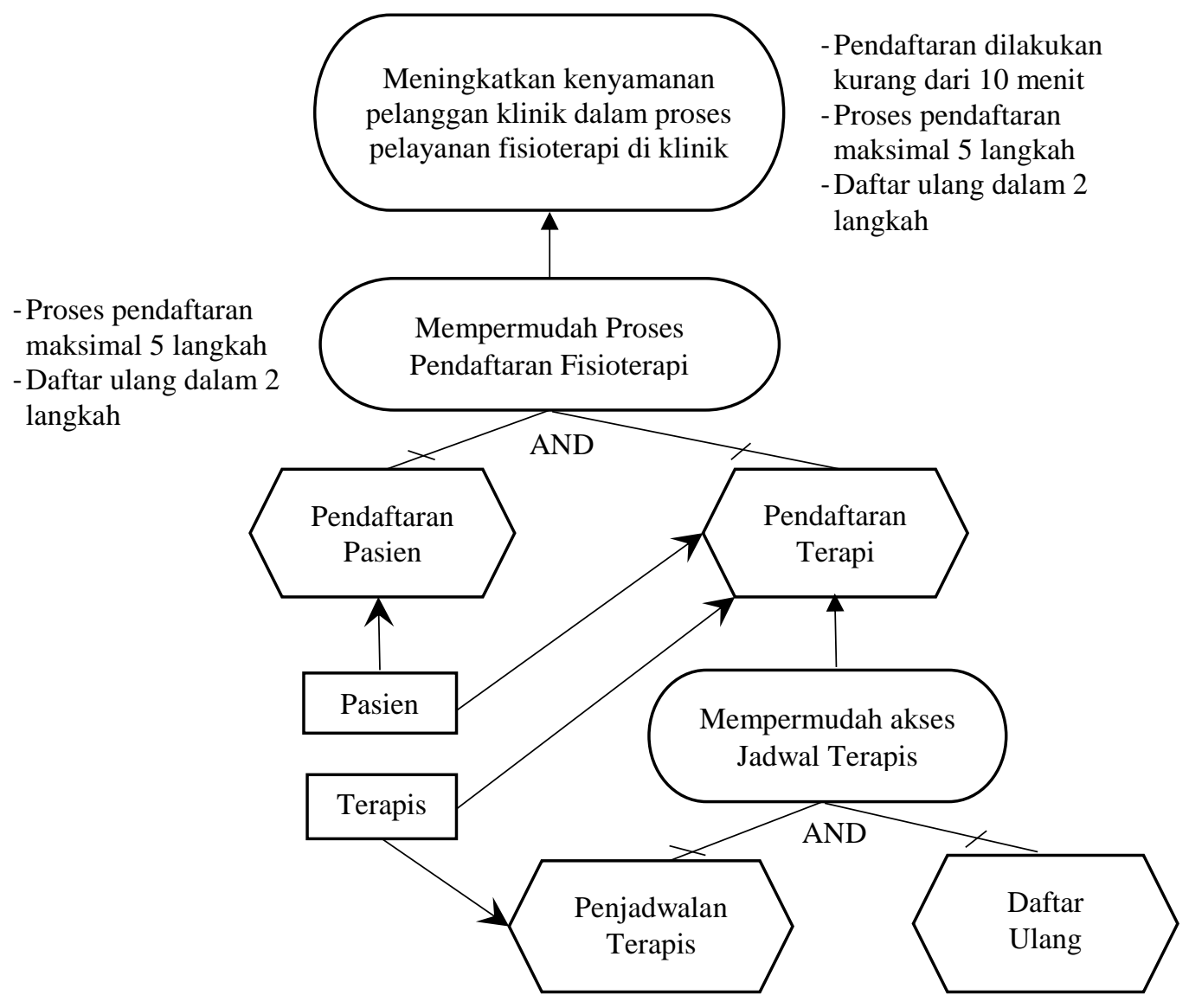

Gambar. 4 Goal tree model sistem pendaftaran klinik

TABEL I

Deskripsi Use Case Pendaftaran Pengguna

\begin{tabular}{|c|c|}
\hline Nama & Pendaftaran Pengguna \\
\hline $\begin{array}{l}\text { Deskripsi } \\
\text { singkat }\end{array}$ & $\begin{array}{l}\text { Seorang pengguna baru (calon pasien di klinik } \\
\text { fisioterapi) melakukan pendaftaran di sistem }\end{array}$ \\
\hline $\begin{array}{l}\text { Kondisi } \\
\text { sebelumnya }\end{array}$ & $\begin{array}{l}\text { Sudah melakukan installlasi aplikasi pada perangkat } \\
\text { telepon pintarnya }\end{array}$ \\
\hline $\begin{array}{l}\text { Kondisi } \\
\text { sesudah }\end{array}$ & $\begin{array}{l}\begin{array}{l}\text { Pengguna terdaftar menjadi pasien di klinik } \\
\text { fisioterapi }\end{array} \\
\end{array}$ \\
\hline $\begin{array}{l}\text { Status sistem } \\
\text { yang } \\
\text { menyebabkan } \\
\text { error }\end{array}$ & $\begin{array}{l}\text { Pengguna sudah terdaftar sebagai pasien di klinik } \\
\text { sebelumnya }\end{array}$ \\
\hline Aktor & Pengguna Baru \\
\hline Pencetus & $\begin{array}{l}\text { Pengguna Baru ingin menjadi pasien di klinik } \\
\text { fisioterapi }\end{array}$ \\
\hline $\begin{array}{l}\text { Proses } \\
\text { standart }\end{array}$ & $\begin{array}{l}\text { 1. Pengguna baru melakukan registrasi } \\
\text { 2. Pengguna memasukan biodata yang diperlukan } \\
\text { 3. Pengguna menyimpan biodata } \\
\text { 4. Pengguna menjadi terdaftar sebagai pasien baru } \\
\text { di klinik fisioterapi }\end{array}$ \\
\hline $\begin{array}{l}\text { Proses } \\
\text { Alternatif }\end{array}$ & $\begin{array}{l}\text { 3'. Pengguna sudah pernah mendaftar sebe-lumnya } \\
\text { (nama, tanggal lahir dan telepon yang sama) } \\
\text { 4'. Melakukan rubah password jika pengguna lupa }\end{array}$ \\
\hline
\end{tabular}

TABEL III

DESKRIPSI USE CASE PENJADWALAN TERAPIS

\begin{tabular}{|l|l|}
\hline \multicolumn{1}{|c|}{ Nama } & \multicolumn{1}{c|}{ Penjadwalan Terapis } \\
\hline $\begin{array}{l}\text { Deskripsi } \\
\text { singkat }\end{array}$ & Admin Klinik memasukan data terkait jadwal terapis \\
\hline $\begin{array}{l}\text { Kondisi } \\
\text { sebelumnya }\end{array}$ & $\begin{array}{l}\text { Sudah ada konfirmasi terapis terkait jadwal yang } \\
\text { akan digunakan pada sistem }\end{array}$ \\
\hline $\begin{array}{l}\text { Kondisi } \\
\text { sesudah }\end{array}$ & Jadwal terapis yang sudah tersimpan di sistem \\
\hline $\begin{array}{l}\text { Status sistem } \\
\text { yang } \\
\text { menyebabkan } \\
\text { error }\end{array}$ & Jadwal terapis pada waktu yang sama \\
\hline Aktor & Admin Klinik \\
\hline Pencetus & Ada terapis yang ingin memasukkan jadwal terbaru \\
\hline $\begin{array}{l}\text { Proses } \\
\text { standart }\end{array}$ & $\begin{array}{l}\text { 1. Admin menerima jadwal dari terapis } \\
\text { Admin memasukkan jadwal pada hari dan jam } \\
\text { yang diminta terapis }\end{array}$ \\
\hline $\begin{array}{l}\text { Proses } \\
\text { Alternatif }\end{array}$ & $\begin{array}{l}\text { 2'. Admin menyimpan jadwal terapis terbaru merubah jadwal yang sudah ada } \\
\text { sebelumnya }\end{array}$ \\
\hline
\end{tabular}


TABEL IIIII

Deskripsi Use CASE PENDAFTARAN TERAPI

\begin{tabular}{|c|c|}
\hline Nama & Pendaftaran Terapi \\
\hline $\begin{array}{l}\text { Deskripsi } \\
\text { singkat }\end{array}$ & $\begin{array}{l}\text { Pasien yang ingin mendaftar untuk sesi terapi pada } \\
\text { jadwal yang tersedia }\end{array}$ \\
\hline $\begin{array}{l}\text { Kondisi } \\
\text { sebelumnya }\end{array}$ & $\begin{array}{l}\text { Pengguna sudah menjadi pasien dan ada jadwal } \\
\text { terapis yang tersedia }\end{array}$ \\
\hline $\begin{array}{l}\text { Kondisi } \\
\text { sesudah }\end{array}$ & $\begin{array}{l}\text { Pasien terdaftar pada jadwal terapis, jadwal terapis } \\
\text { pada waktu tersebut tidak tersedia lagi untuk } \\
\text { pendaftaran pasien lain }\end{array}$ \\
\hline $\begin{array}{l}\text { Status sistem } \\
\text { yang } \\
\text { menyebabkan } \\
\text { error }\end{array}$ & Tidak ada jadwal terapis yang tersedia \\
\hline Aktor & Pasien \\
\hline Pencetus & Ada pasien yang ingin mendaftar sesi terapi \\
\hline $\begin{array}{l}\text { Proses } \\
\text { standart }\end{array}$ & $\begin{array}{l}\text { 1. Pasien melihat ada jadwal terapis yang tersedia } \\
\text { 2. Pasien mendaftar pada jadwal terapis yang } \\
\text { tersedia } \\
\text { 3. Pasien mendapatkan konfirmasi pendaftaran (QR } \\
\text { Code) }\end{array}$ \\
\hline $\begin{array}{l}\text { Proses } \\
\text { Alternatif }\end{array}$ & - \\
\hline
\end{tabular}

TABEL IVV

DESKRIPSI USE CASE DAFTAR ULANG

\begin{tabular}{|l|l|}
\hline \multicolumn{1}{|c|}{ Nama } & \multicolumn{1}{c|}{ Daftar Ulang } \\
\hline $\begin{array}{l}\text { Deskripsi } \\
\text { singkat }\end{array}$ & $\begin{array}{l}\text { Pasien yang sudah datang di Klinik dan siap } \\
\text { mengikuti sesi terapi }\end{array}$ \\
\hline $\begin{array}{l}\text { Kondisi } \\
\text { sebelumnya }\end{array}$ & $\begin{array}{l}\text { Pasien sudah terkonfirmasi untuk pendaftaran sesi } \\
\text { terapi }\end{array}$ \\
\hline $\begin{array}{l}\text { Kondisi } \\
\text { sesudah }\end{array}$ & $\begin{array}{l}\text { Pasien terdaftar ulang dan siap dipanggil untuk sesi } \\
\text { terapi }\end{array}$ \\
\hline $\begin{array}{l}\text { Status sistem } \\
\text { yang } \\
\text { menyebabkan } \\
\text { error }\end{array}$ & QR Code tidak terdaftar pada sistem \\
\hline Aktor & Pasien dan Admin Klinik \\
\hline $\begin{array}{l}\text { Pencetus } \\
\text { Kda pasien yang ingin mendaftar ulang sesi terapi di }\end{array}$ \\
\hline $\begin{array}{l}\text { Proses } \\
\text { standart }\end{array}$ & $\begin{array}{l}\text { 1. Pasien sudah mendapat QR Code daftar ulang } \\
\text { Pasien melapor pada Admin Klinik untuk scan } \\
\text { QR Code }\end{array}$ \\
\hline $\begin{array}{l}\text { Proses } \\
\text { Alternatif }\end{array}$ & \begin{tabular}{l} 
Pasien menunggu panggilan untuk sesi terapi \\
\hline
\end{tabular} \\
\hline
\end{tabular}

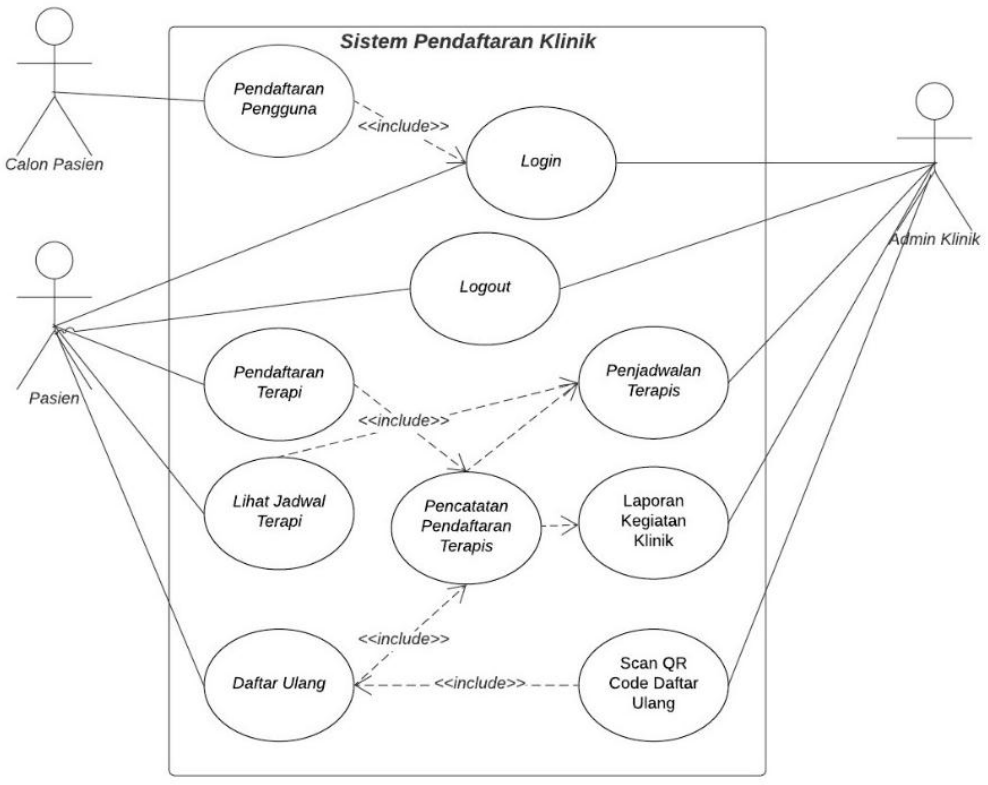

Gambar. 5 Use case digaram sistem pendaftaran klinik

Setelah Use Case Digaram, tahap berikutnya mendifinisikan ER-Diagram untuk rancangan basis data yang digunakan pada sistem. Tabel yang dirancang pada sistem ini terdiri dari 4 tabel yang saling berhubungan (Gambar 6). Sesudah selesai proses perancangan fungsional dan basis data, maka berikutnya adalah melakukan konstruksi (coding) dari sistem.

Konstruksi sistem Android yang digunakan pasien klinik menggunakan Android Studio dan untuk aplikasi admin klinik berbasiskan Web menggunakan editor PHP, HTML dan CSS. Tahapan konstruksi ini terdiri dari 4 tahapan yang setiap tahapannya akan dicobakan ke penggunanya sampai tahap akhir yaitu tahap cut over (peralihan) untuk di-implementasikan. 


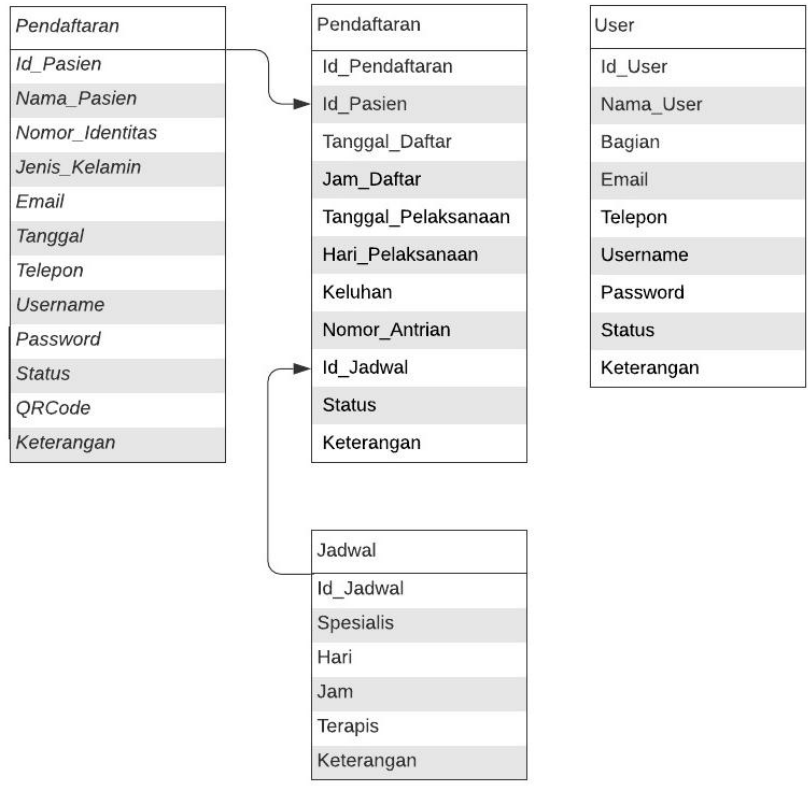

Gambar. 6 Entity relationship digaram sistem pendaftaran klinik

4 (empat) tahapan tersebut yaitu :

1) Tahap Inisialisasi: Pada tahap kontruksi pertama (inisiasi) yang ditunjukkan kepada Admin Klinik, Admin Klinik mencoba menu-menu utama yang ada di sistem, dari mulai tambah admin, mengatur jadwal terapi sampai melihat data pendaftaran pada hari itu. Setelah selesai dicoba, admin ditanyakan umpan baliknya dan salah satu umpan baliknya yaitu admin meminta dibuatkan menu Laporan untuk dapat melihat data pasien dalam periode tertentu.

2) Tahap Kedua: Pada tahap ini, sistem admin sudah ditambahkan fungsi untuk membuat laporan data pasien dalam periode tertentu. Admin klinik kemudian kembali mencoba dan sudah tidak ada umpan balik dari mereka.

3) Tahap Ketiga: Pada kontruksi tahap ketiga sudah melakukan uji coba antar muka sistem Androidnya kepada salah satu pasien dan juga Kepala Klinik. Para pengguna mencoba berbagai tombol menu yang sudah ada untuk menguji apakah tombol yang di sediakan sudah berfungsi sesuai kebutuhan. Masih ada beberapa umpan balik seperti fungsi yang belum berjalan sempurna dan tampilan yang perlu disesuaikan lagi.

4) Tahap Keempat: Pada tahap ini, hasil kontruksi tahap keempat berupa sistem Android yang digunakan Admin Klinik untuk scan QR Code yang dimiliki pasien. Admin Klinik melakukan umpan balik pada bagian antar muka scan. Admin Klinik meminta saat telah melakukan Scan QR Code datanya akan langsung masuk ke sistem admin tanpa perlu di input ulang lagi.

Sesudah keempat tahapan di atas, berikutnya konstruksi memasuki tahapan peralihan (cut over). Tahapa ini merupakan tahap akhir dalam metode pengembangan sistem RAD (Rapid Application Development). Sistem yang telah berhasil dibangun siap untuk diuji coba pada lingkungan nyata.

\section{Implementasi}

Proses berikutnya dari RAD adalah proses implementasi atau proses uji coba terhadap sistem yang selesai dikonstruksi. Uji coba dilakukan dengan menggunakan metode Blackbox. Blackbox merupakan pengujian perangkat lunak dari sisi spesifikasi fungsional tanpa menguji desain dan kode program untuk mengetahui apakah fungsi, masukan dan keluaran dari perangkat lunak sesuai dengan spesifikasi (kebutuhan) yang dibutuhkan[16].

Pada metode Blackbox, pengujian antar muka sistem bertujuan untuk mengetahui fungsionalitas pada elemenelemen antar muka yang terdapat pada setiap halaman sistem. Elemen-elemen ini akan diujikan terutama pada elemen tombol fungsi/menu yang tersedia pada sistem untuk memastikan setiap tombol/menu berjalan sesuai dengan spesfikasinya.

Seperti yang sudah dijelaskan pada bagian-bagian sebelumnya, ada 2 bagian sistem, yang pertama sistem Admin Klinik dan Sistem Pendaftaran berbasis Android. Beberapa uji coba fungsi utama akan dijelaskan sebagai berikut:

1. Fungsi login untuk fitur keamanan pengguna di Sistem Admin Klinik. Setiap pengguna wajib login terlebih dahulu untuk dapat melakukan penambahan akun admin lain, menggunakan menu pasien yang digunakan untuk mengubah data pasien, menu jadwal untuk menginput jadwal terapi dan nama terapis yang sudah di tentukan, menu pendaftaran untuk melihat pasien yang mendaftar pada hari itu, dan menu laporan untuk melihat data pasien yang sudah selesai melakukan terapi (Gambar 7).

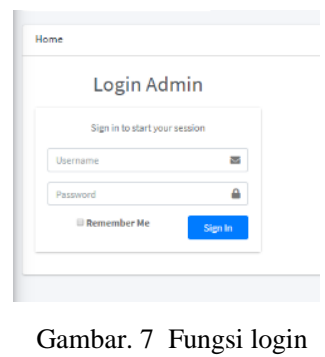

2. Fungsi penjadwalan terapis yang terdapat dua halaman, yang pertama untuk melakukan input data baru dan fungsi lainnya untuk melihat jadwal terapis harian. Pada halaman input, admin klinik dapat menambahkan jadwal terapi beserta dengan nama terapisnya serta spesialisnya, dengan cara mengisi data sesuai tabel yang tersedia, sedangkan untuk data harian admn dapat melihat jadwal yang sudah berhasil di input ke dalam sistem (Gambar 8). 

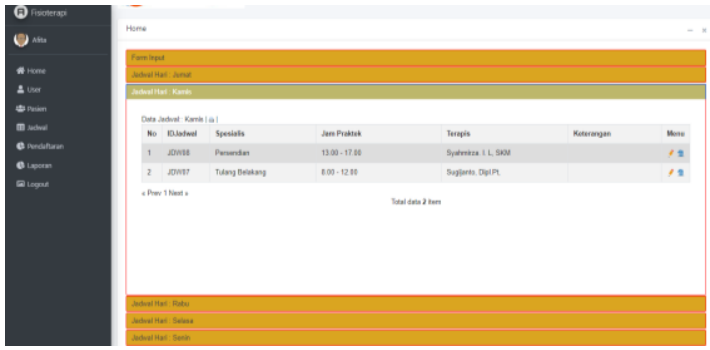

Gambar. 8 Fungsi jadwal terapis

3. Laporan kegiatan klinik Fisioterapi, Admin klinik dapat melihat data pasien yang sudah selesai melakukan terapi di Klinik Fisioterapi, admin juga dapat melihat data sesuai periode yang diinginkan, serta ada fungsi cetak jika admin membutuhkan data tersebut untuk dicetak dan diberikan kepada kepala klinik (Gambar 9).

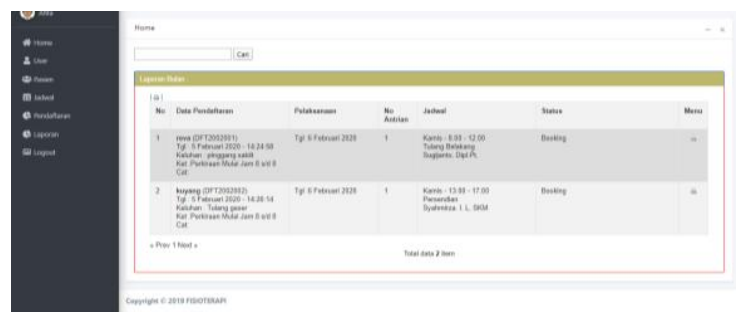

Gambar. 9 Laporan klinik fisioterapi

4. Halaman utama dari Sistem Android ketika berhasil login terdapat menu jadwal terapi, pendaftaran terapi, history pasien dan logout (Gambar 10).

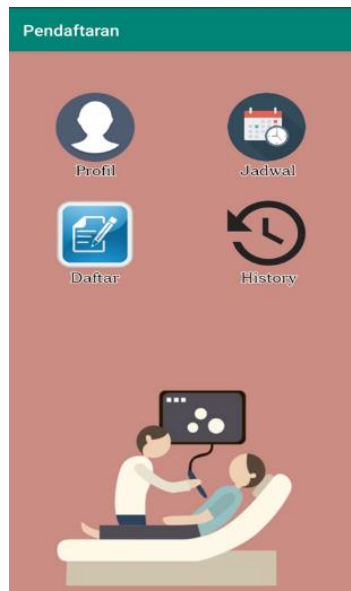

Gambar. 10 Menu utama sistem pendaftaran klinik fisioterapi berbasis android

5. Menu untuk melihat masuk ke halaman Profil dari pasien yang menunjukkan data diri pasien, terdiri dari nama, nomor identitas, jenis kelamin, tangal lahir, email, nomor telepon, username dan password. Pada halaman ini juga menampilkan $Q R$ Code pasien yang nantinya akan di gunakan sebagai daftar ulang ketika pasien sudah sampai di tempat terapi. Nantinya pasien hanya perlu menunjukan $Q R$ Code ini ke pada admin/ petugas lalu akan di scan sebagai bukti telah hadir di tempat terapi (Gambar 11).

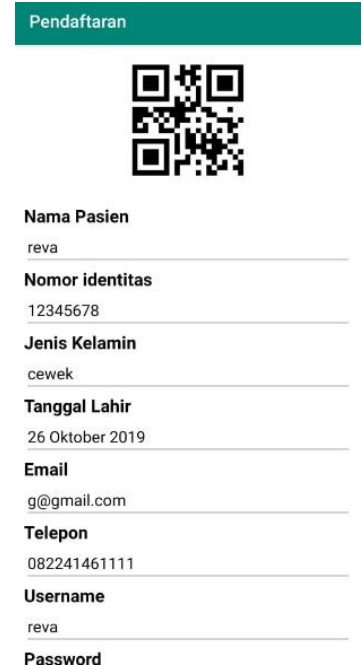

Gambar. 11 Halaman profil sistem pendaftaran klinik fisioterapi berbasis android

6. Menu untuk melihat jadwal terapi untuk memudahkan dalam mendaftar pasien di anjurkan untuk mengakses menu jadwal agar dapat melihat list jadwal terapi yang ada di Klinik Fisioterapi, jika pasien sudah menentukan jenis terapi yang di inginkan selanjutnya pasien melakukan proses pendaftaran dengan kembali ke menu home, lalu klik icon daftar (Gambar 12).

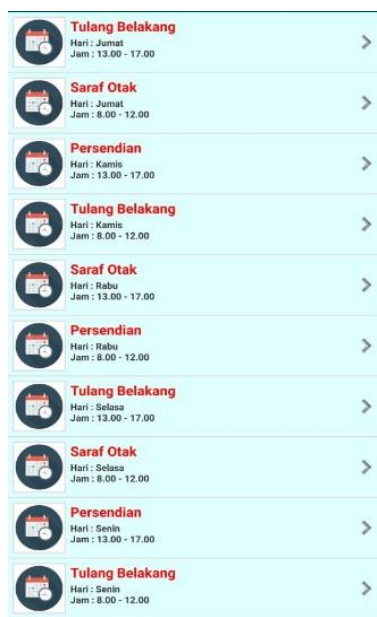

Gambar. 12 Halaman jadwal terapi sistem pendaftaran klinik fisioterapi berbasis android

7. Menu untuk daftar terapi, tempat untuk pasien dapat mendaftar terapi dengan cara memilih jenis terapi, lalu tanggal yang di inginkan, serta keluhan apa yang sedang di alami oleh pasien. Jika data yang di isikan sudah benar secara otomatis data pendaftaran tersebut akan masuk ke dalam sistem, lalu pasien akan menerima konfirmasi bahwa jadwal terapi yang di pilih sudah berhasil di daftarkan. Nantinya pasien akan mendapatkan keterangan waktu yang sudah di tentukan oleh sistem untuk datang ke tempat terapi (Gambar 13). 


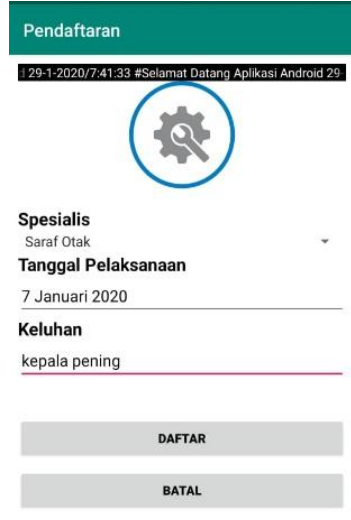

Gambar. 13 Halaman daftar terapi sistem pendaftaran klinik fisioterapi berbasis android

8. Menu untuk melihat sejarah melakukan terapi berisi tentang daftar pendaftaran yang sudah pernah pasien lakukan sebelumnya.

9. Menu untuk Scan Barcode hanya ada pada menu utama jika yang login adalah admin klinik (Gambar 14).

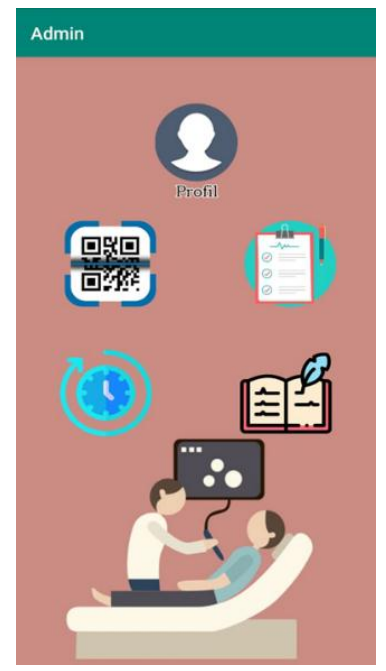

Gambar. 14 Halaman menu admin klinik sistem pendaftaran klinik fisioterapi berbasis android

\section{KESIMPULAN}

Berdasarkan penjelasan diatas, maka kesimpulan dari penelitian ini adalah:

1. Sistem ini dapat mempermudah pasien yang ingin mendaftar terapi di Klinik Fisioterapi, karena dalam sistem ini sudah menyediakan info jadwal terapis. Pasien dapat mendaftar langsung tanpa proses konfirmasi telepon ke admin klinik.

2. Sistem ini dapat mempermudah pasien yang sudah datang untuk mendaftar ulang dengan mengguna-kan QR Code sebagai alat bantu identifikasi sehingga admin klinik juga lebih mudah melakukan pencatatan di sistem.
3. Sistem yang dikembangkan sudah memenuhi kebutuhan-kebutuhan (spesifikasi) awal yang telah ditetapkan menggunakan metode OGORE, sehingga sistem ini memenuhi kebutuhan organisasi untuk meningkatkan pelayanan kesehatan kepada masyarakat khususnya yang membutuhkan pelayanan fisioterapi.

\section{REFERENSI}

[1] N. I. Arovah, "Dasar-Dasar Fisioterapi pada Cedera Olahraga," Fisioterapi, pp. 22-26, 2010.

[2] Universitas Esa Unggul, "Klinik Fisioterapi Universitas Esa Unggul," 2012. https://www.esaunggul.ac.id/klinik-fisioterapi/ (accessed Jun. 26, 2020).

[3] Universitas Esa Unggul, "Irfan Bachdim Jalani Terapi di Klinik Fisioterapi Universitas Esa Unggul," Universitas Esa Unggul, 2016. https://www.esaunggul.ac.id/irfan-bachdim-jalani-terapi-diklinik-fisioterapi-universitas-esa-unggul/ (accessed Jun. 26, 2020).

[4] R. S. Prabowo, "Libur Lebaran Dimaksimalkan Bayu Pradana untuk Pulihkan Cedera," Indosport.com, 2019. https://www.indosport.com/sepakbola/20190604/libur-lebarandimaksimalkan-bayu-pradana-untuk-pulihkan-cedera (accessed Jun. 26, 2020).

[5] StatCounter, "Mobile Operating System Market Share Worldwide," $2020 . \quad$ https://gs.statcounter.com/os-marketshare/mobile/worldwide (accessed Jun. 26, 2020).

[6] F. Adikara, Sandfreni, A. Anggarani, and Ernawati, "Qualitative requirements analysis process in organization goal-oriented requirements engineering (OGORE) for E-commerce development," in IT Convergence and Security 2017. Lecture Notes in Electrical Engineering., vol. 449, K. Kim, H. Kim, and N. Baek, Eds. Singapore: Springer, 2017, pp. 318-324.

[7] W. S. Davis, D. C. Yen, D. C. Yen, and W. S. Davis, "Rapid application development (RAD)," in The Information System Consultant's Handbook, 2020.

[8] F. Adikara, B. Sitohang, and B. Hendradjaya, "Penerapan Goal Oriented Requirements Engineering ( GORE ) Model ( Studi Kasus : Pengembangan Sistem Informasi Penjaminan Mutu Dosen ( SIPMD ) pada Institusi Pendidikan Tinggi )," in Seminar Nasional Sistem Informasi Indonesia, 2013, pp. 230-235.

[9] A. Van Lamsweerde, "From System Goals to Software Architecture," Form. Methods Softw. Archit., vol. 2804, pp. 25-43, 2003, doi: 10.1007/b13225.

[10] D. Amyot, S. Ghanavati, J. Horkoff, G. Mussbacher, L. Peyton, and E. Yu, "Evaluating goal models within the goal-oriented requirement language," Int. J. Intell. Syst., vol. 25, no. 8, pp. 841877, 2010, doi: 10.1002/int.20433.

[11] F. Adikara, B. Hendradjaya, and B. Sitohang, "Using organization goal-oriented requirements engineering result to develop sales information system," in Lecture Notes in Engineering and Computer Science, 2017, vol. 2227.

[12] M. Destiningrum and Q. J. Adrian, "Sistem Informasi Penjadwalan Dokter Berbassis Web Dengan Menggunakan Framework Codeigniter (Studi Kasus: Rumah Sakit Yukum Medical Centre)," J. Teknoinfo, 2017, doi: 10.33365/jti.v11i2.24.

[13] R. R. M. Salim, "Pengembangan Sistem Informasi Klinik Berbasis Web," in Seminar Nasional Sistem Informasi Indonesia, 2013, pp. $2-4$.

[14] A. Fatkhudin and D. N. Alifiani, "Sistem Informasi Pendaftaran Pasien pada Klinik dr. Veri Kajen Kabupaten Pekalongan Berbasis Android," J. Ilm. Edutic, vol. 4, no. 1, pp. 51-58, 2017.

[15] TechTerm, "QR Code," 2015. https://techterms.com/definition/qr_code (accessed Jun. 26, 2020).

[16] I. Sommerville, Software engineering (10th edition). 2016 